\title{
Marching toward the Millennium Development Goals: What about Health Systems, Health-Seeking Behaviours and Health Service Utilization in Pakistan?
}

\author{
Babar T. Shaikh, Assistant Professor, Aga Khan University, Karachi, Pakistan \\ Dr. Babar T. Shaikh, Assistant Professor, Director, Health Policy and Management Program, \\ Department of Community Health Sciences, Aga Khan University, Stadium Road, PO Box 3500, \\ Karachi 74800, Pakistan, Tel: +92.21.4930051 Ext: 4899, 4811; Direct: +92.21.4864899; \\ Fax: +92.21.4934294-4932095, email: babar.shaikh@aku.edu
}

\begin{abstract}
Attaining the ambitious targets pronounced in the Millennium Development Goals (MDGs) will necessitate radical changes in policy as well as extensive reforms and strong inter-sectoral coordination in the healthcare system of Pakistan. While aiming for such macro-level achievements, it is imperative to analyze the on-the-ground realities of any health system. Improving health systems has the potential to assist progress toward MDGs in the near term by promoting more equitable access and introducing effective interventions. More money allocation and more health spending would not necessarily mean better health for Pakistanis. The complex composition of the healthcare system drives us to study the intricate phenomena of health service utilization and healthcare-seeking behaviours. Such an approach will thus provide evidence to sensitize health personnel to provide more empathetic care and to encourage the community at large to start seeking appropriate and timely healthcare. This paper advocates thinking beyond health services provision by reaching out to people and understanding their perceptions, practices and health-seeking behaviours. Achieving millennium development goals will necessitate interventions that address health issues of women, children and all other vulnerable groups in Pakistan.
\end{abstract}

\section{The Context}

In September 2000, the United Nations General Assembly adopted a number of resolutions aimed at alleviating poverty and promoting equitable and sustainable development in developing countries. 
One of these resolutions identified eight areas for concrete action, with measurable results to be achieved by the year 2015. All 189 member states of the United Nations endorsed these Millennium Development Goals (MDGs) and vowed to make concerted efforts to achieve them (United Nations 2001). In subsequent meetings to monitor progress toward MDGs, further pledges and endorsements came from the member states. Three of the eight MDGs are unequivocally health related: Goals 4 and 5 call for a two-thirds reduction in the under-five child mortality rate and a threequarters reduction in the maternal mortality ratio by 2015. Goal 6 is to combat HIV/AIDS, malaria and other diseases. The first three MDGs have an indirect impact on health: eradicating poverty and hunger (Goal 1), achieving universal primary education (Goal 2) and promoting gender equality and empowerment of women (Goal 3). The indirect relationship to health of the first three goals requires thinking about a holistic approach to the MDGs. (See Table 1 for a complete list of MDGs.)

Progress toward the MDGs for health has so far been mixed and will not necessarily be swifter in the second half of the 1990-2015 window (World Bank 2004). Health systems constraints are impeding the implementation of major global initiatives for health and the attainment of MDGs. Health systems research could potentially contribute to overcoming these barriers (Task Force on Health Systems Research 2004). The ambitious targets pronounced in MDGs will need fundamental changes in policy, as well as extensive reforms and strong inter-sectoral coordination in the health system of Pakistan. While aiming for such macro-level achievements, it is crucial to analyze the ground realities of any health system. Improving health systems has the potential to assist progress toward MDGs in the near term by promoting more equitable access and introducing effective interventions. This can be made possible by thinking beyond health services provision and reaching out to people and understanding their perceptions, practices and behaviours (World Health Organization [WHO] 2005a). The aim of this paper is to present an account of the health system, health-seeking behaviours and health service utilization in Pakistan, and to find out the issues in order to address the requisites and to accelerate the progress toward MDGs.

Table 1. The eight millennium development goals

\begin{tabular}{|l|l|}
\hline Goal 1 & Eradicate extreme poverty and hunger \\
\hline Goal $\mathbf{2}$ & Achieve universal primary education \\
\hline Goal $\mathbf{3}$ & Promote gender equity and empower women \\
\hline Goal $\mathbf{4}$ & Reduce child mortality \\
\hline Goal 5 & Improve maternal health \\
\hline Goal $\mathbf{6}$ & Combat HIV/AIDS, malaria and other diseases \\
\hline Goal 7 & Ensure environmental sustainability \\
\hline Goal 8 & Develop a global partnership for development \\
\hline
\end{tabular}

\section{Methodology}

This paper is based on a review of peer-reviewed literature published after the MDGs were institutionalized. Articles were searched using MEDLINE and Google. A combination of the following keywords was used: millennium development goals, health systems, health policy, health-seeking behaviours, developing countries and Pakistan. Also, official documents and reports from the Government of Pakistan have been critically reviewed, and official documents and reports from the WHO, the World Bank and other international organizations have been referred to. A brief preamble about Pakistan's healthcare system is presented, with emphasis on health-seeking behav- 
iours and health service utilization trends in the country. Conclusions are drawn on the basis of recommendations presented by the international community, success stories of various states and lessons learned so far en route to achieve the MDGs by 2015.

\section{A snapshot of the health system, health-seeking behaviours and health service utilization}

The healthcare system in Pakistan comprises public as well as private health facilities. The system includes an elaborate network of dispensaries and basic health units (BHUs) (serving a population of 10,000-20,000) and rural health centres (RHCs) (serving 25,000-50,000). The next levels of referral are the taluka/tehsil hospitals (serving $0.5-1$ million people) and the tertiary-level hospitals (serving 1-2 million). However, these basic-level facilities have restricted hours of operation and are often located far away from the population. For years, health facilities in the public sector lacked trained personnel, proper equipment, adequate medicines and a structured system of referral (Khan 1996; World Bank 1997). The public sector healthcare system remains underutilized, in spite of a large infrastructure (Government of Pakistan 2000a; Government of Pakistan 2001).

The nationwide network of medical services consists of 796 hospitals, 482 RHCs, 4616 BHUs and 4144 dispensaries. These are staffed by approximately 90,000 doctors, 3000 dentists, 28,000 nurses, 6000 Lady Health Visitors and 24,000 midwives (Government of Pakistan 2001). For years, Pakistan has been spending less than $1 \%$ of its Gross National Product on the health sector, one of the lowest rates in South Asia. A major chunk of health spending goes to salaries and operational costs (United Nations Development Programme 2005; Government of Pakistan 2006).

Good governance has also been an unrelieved issue in the health system, which is characterized by lack of continuity and adherence to policies (Government of Pakistan 2002). The social unacceptability of these centres has been due to a dearth of female staff in facilities (Gezairy 2004). In the private sector, besides few accredited hospitals, unregulated outlets and hospitals, scores of general practitioners, homeopaths, traditional/spiritual healers, Unani (Greco-Arab) healers, herbalists, bonesetters and quacks provide unchecked healthcare. A majority prefers consulting these healthcare facilities and providers for number of reasons, mainly for quality and compassionate care (Shaikh, Rabbani and Rahim 2006). Thus bringing about change in health-seeking behaviours and practices has been an uphill journey. The cost barrier has been crucial in accessibility and affordability of effective and quality health services (Shaikh and Hatcher 2005). Annual spending on health is nearly $\$ 17$ per capita, of which $\$ 13$ comes out of the patient's pocket (WHO 2006). The provision of accessible and affordable health services has often been cited as a high priority for poor communities in Pakistan. However, the crisis has never been dealt with on an emergency footing (Government of Pakistan 2003).

Since 2000 , the health portfolio has been given to the districts, decentralizing the financial as well as administrative powers in the system (Government of Pakistan 2000b). These district health systems have so far been struggling to cope with the pressure of the colossal tasks assigned to them. Pakistan's health system was ranked 122nd of 191 in the WHO health systems performance rating in 2000, which was not praise-worthy at all (WHO 2000a). A coherent health system capable of addressing the real health needs of the people is yet to emerge.

Strategic planning and policy formulation in the healthcare system, however, must be based on knowledge of what determines people's health-seeking and health system utilization behaviour. These factors originate within the institutions of family, community and the healthcare system. Factors determining health behaviours may be seen in various contexts: physical, socio-economic, cultural and political (Kroeger 1983). Keeping in view this depiction of Pakistan's health system, we discuss and analyze the readiness to achieve Goals 4, 5 and 6 in light of determinants of healthcareseeking and health service utilization studies in Pakistan.

\section{Goal 4: Two-Thirds Reduction of under-5 Child Mortality Rate}

Infant, child and maternal mortality in Pakistan has been one of the highest in the region and in 
the developing world. However, progress though slow is visible. The infant mortality rate of over 100/1000 live births in the 1990s has gone down to 78/1000 live births (National Institute of Population Studies [NIPS] 2007). Yet a considerable number of children are dying of diarrhea, acute respiratory infections and tetanus. The under-five mortality rate has gone down from 128/1000 live births in the 1990s to 94/1000 live births. This decline is mainly due to the encouraging level of the knowledge regarding immunization, especially in urban areas, but achieving universal immunization has been a big challenge in Pakistan. The routine immunization coverage for children aged 12-23 months is below $50 \%$, and thus $10 \%$ of children do not reach their fifth birthday (National Institute of Health 2003). The expanded program of immunization (EPI) has been facing disheartening constraints in implementation. Moreover, malnutrition and micro-nutrient deficiencies also account for many deaths in Pakistan (Bhutta 2004). Bottle-feeding among children below 3 years is widespread. Promotion of breastfeeding and practices related to complementary feeding at the appropriate age would markedly reduce wasting and stunting among children (Black et al. 2008).

Poverty and illiteracy have been the major barriers in mobilizing people to look after their children's nutrition and immunization (Zaidi et al. 2004). Poor quality of services, inadequate referral systems, lack of integration among various vertical programs and inadequate resource allocation to EPI are some of the service-related or political problems that have never been determinedly addressed (World Bank 1997; Mangrio et al. 2007). Persistent under-utilization of public sector health facilities has contributed also over a period of time to the gravity of the situation (Government of Pakistan 1993; Government of Pakistan 2000a). Poverty, inadequate housing, lack of drinking water and sanitation facilities have had a profound impact on health of children (World Bank 2002). Among other factors prevailing at the community level, gender discrimination in child rearing, nutrition and healthcare seeking is still remarkably noticeable, especially in rural areas (Hunte and Sultana 1992). As in all other developing countries and restricted cultures, lack of mobility is another barrier to women seeking healthcare for themselves and their children, even in matters of utmost importance such as immunization or in emergencies. Distance to the nearest health facility, the availability of transport and the cost incurred in one round trip are genuine concerns (Shaikh and Hatcher 2005). EPI administration and coverage can be improved through mass campaigns but necessitates strengthening of health systems, enhancing political commitment and raising awareness among the masses. Working with private sector medical practitioners and traditional healers (through regulations and setting standards), to whom people often resort for healthcare (Waters et al. 2002), must be considered.

\section{Goal 5: Three-quarters Reduction in Maternal Morality Ratio}

This is the MDG where most countries have demonstrated unsatisfactory progress. More than 500,000 women die every year from pregnancy-related causes, and more than $99 \%$ of these deaths take place in the developing world (Population Action International 2005). The United Nations Children's Education Fund (UNICEF) (2007) and the NIPS (2007) in Pakistan simultaneously reported a high fertility rate and one of the lowest contraceptive prevalence rates $(25 \%)$ in the world. This results in a huge number of unwanted pregnancies, which cause women to resort to unsafe abortions. In Pakistan abortion is illegal; therefore these women fall prey to unskilled providers in an unhygienic and unsafe environment, and the result is obvious (Fikree et al. 1994; Saleem and Fikree 2001).

According to the NIPS (2007), seeking antenatal care is still not universal (60\%). Similarly, maternal tetanus toxoid vaccination should be an essential component of antenatal care in Pakistan, yet only $6 \%$ of babies delivered are reported to be fully protected against neonatal tetanus (NIPS 2007). Nonetheless, the maternal mortality ratio in Pakistan has declined considerably, from over $600 / 100,000$ live births in the 1960s to 340/100,000 live births at the dawn of 21st century (World Bank 2000). However, the challenges have been enormous. There is a dearth of obstetric facilities for women in the basic health units and rural health centres (World Bank 1997). The Pakistan Medical Research Council's national health survey (1998) showed that an average Pakistani female calls on 
a healthcare provider of any cadre six times a year (which is even higher than males in Pakistan). Reproductive health issues aside, she faces perpetual ill health, generalized weakness, depression and anxiety due to domestic and sexual violence (Mirza and Jenkins 2004). Yet the physical distance to the facility, lack of socio-cultural acceptability of the health services and need for round-the-clock emergency obstetric services remain unaddressed. Only $25 \%$ of primary healthcare facilities are staffed by qualified female health providers (Islam and Tahir 2002). Maybe that is why we see only $34 \%$ of deliveries conducted in healthcare facilities. Ensuring 24-hour emergency obstetric care, presence of a skilled attendant at birth and availability of post-abortion services could save many lives (World Bank 2005a).

Gender discrimination through the life cycle of a South Asian female determines her health status and outcomes (Shaikh, Hatcher and Haran 2006). Education could have made an impact on women's lives, but so far the female literacy rate is just 32\% (Government of Pakistan 1998). The status of women is still to be acknowledged fully, whether it be her reproductive role or her basic rights to nutrition, health and education (Tinker 1998). Malnutrition and anemia are commonly seen among poor women and are significant factors contributing to morbidity and mortality. Programs and interventions at the community level must focus on advocacy to improve antenatal care-seeking and acceptance of family planning services.

\section{Goal 6: Combat HIV/AIDS, Malaria and Other Diseases}

Pakistan has a low to moderate seroprevalance of HIV/AIDS, unlike its neighbours in the region. Among diagnosed cases, males predominate (87\%), most belonging to the 20-40 age group (Hyder et al. 1999). Heterosexual activity has been recognized as the principal mode of viral transmission, and the groups exhibiting high-risk behaviour include commercial sex workers, intravenous drug users, jail mates and professional blood donors. The detection of HIV has initiated a multi-sectoral response involving the government and non-governmental and donor agencies (Kazi et al. 2000). In Pakistan, women's low social status and their lack of negotiating power expose them to the risk of unprotected intercourse, a known risk factor for developing HIV. Moreover, there is a poor level of risk recognition and individual susceptibility to HIV among the general population (Sheikh et al. 2003). To address the complexity of the problem, culturally acceptable strategies need to be adopted, addressing the existing modes of HIV transmission. In 1993, the World Bank suggested investing in culture-specific interventions to adopt a comprehensive strategy for HIV/AIDS prevention (World Bank 1993).

As for malaria, the WHO has been recommending a multi-pronged strategy to combat the disease, including new medicines, vaccines, improvements in healthcare systems and insecticidetreated nets (ITNs) since 1997 (WHO 2000b; WHO 2002). Though no sound data is available in Pakistan, we know that malaria is one of the principal causes of anemia during pregnancy and may result in abortions and still births (Steketee et al. 2001). Women and children belonging to low income communities and residing in malaria-prone areas in urban slums and rural habitats appear to be the most vulnerable group. A behavioural change campaign for promoting use of ITNs can save substantial resources needed for treating the illness and its complications. ITNs ought to be available to the most vulnerable at subsidized costs or in easy installments; government investment would be required and donors would have to be mobilized.

\section{Discussion}

Besides the three goals related directly to health, the first three goals - eradicating poverty and hunger (Goal 1), achieving universal primary education (Goal 2), and promoting gender equality and empowerment of women (Goal 3) would also be accounted for in rethinking strategies to reform our health system. Various international treaties and conferences ratified that the rights of women to information and education, to decide about fertility, to access healthcare and to benefit from scientific progress must be ensured. Meaningful and strong inter-sectoral collaboration would be required to achieve such ambitious targets set out in MDGs, thus culminating in better health outcomes.

An approach suggested by Siddiqi et al. (2004) would involve non-governmental organizations, 
donors and other stakeholders from civil society to combine efforts and address a complex horde of issues around reproductive health. More money allocation and more health spending would not necessarily mean better health. This is because of deep structural problems in our health sector that need rapid removal (Clemens and Moss 2004). Progress toward MDGs will require political and economic reforms in the civil service and governance structures, and a just allocation of resources to health in the national expenditure framework (Dodd and Cassels 2006). Whether it is a matter of introducing reforms or designing interventions, with the help of evidence-based research, researchers can influence the policy-making process (Nishtar 2006). The international community maintains that good health is a human right and that investing in health is the key to sustainable development; it should also strive to work in close partnership with governments and build their capacity to address the challenges and constraints to achieving reasonably well the targets set for each of the MDGs.

All these goals necessitate consequential policies to improve the status of women in Pakistan, who constitute almost half of the population. Improving the health and thus the productive potential of Pakistani women will play a vital role in all aspects of the country's development and economic upsurge. As we approach the halfway point of the 15-year period in the new millennium, efforts to strengthen immunization programs and expand health services must be amplified to the maximum, and quality maternal health services must be made widely accessible (United Nations 2007). Today, the consensus of the international community is to gear all efforts toward building the equitable, effective and client-friendly health systems required to achieve the MDGs. Investing in health necessitates in-depth research to visualize the real determinants of health-seeking behaviours and health services utilization among the most vulnerable sub-groups of the population. Moreover, very few public sector programs and interventions are subjected to rigorous, independent evaluation, which should be the foremost ingredient of any program to facilitate the choice of interventions to achieve the MDGs (World Bank 2005b).

Social marketing is not a new phenomenon in Pakistan; promoting contraceptive use for furthering family planning, use of oral rehydration salt to reduce childhood mortality from diarrhea and use of iodized salts in goiter-endemic areas are some of the more successful campaigns in which the government and the private sector have been involved. Lessons learned from these successful campaigns suggest a rationale for using various methods of disseminating information for bringing about a positive change in health-seeking behaviours (Husain and Shaikh 2005; Qazi and Shaikh 2007).

Customs, values, needs and priorities of the communities ought to be taken into consideration while reshaping the health system or revisiting policies. For the $66 \%$ of the population living in rural areas, poverty, along with illiteracy, low status of women and inadequate water and sanitation facilities have in actuality slowed down the improvement in health indicators in Pakistan (World Bank 2002). In the latest MDG monitoring report by the World Bank, emphasis has again been placed on gender equality and women's empowerment, which are not only crucial for women's own health, but also vital for other millennium goals - halving poverty, achieving primary education for all and lowering the under-five mortality rate (World Bank 2007). The complex composition of the healthcare system drives us to study the most intricate phenomenon of healthcare-seeking behaviours and health service utilization. Such an approach will thus provide evidence to sensitize the healthcare personnel to provide more empathetic care and to encourage the community at large to start seeking appropriate and timely healthcare.

Health workers must take responsibility for improving healthcare delivery in this highly pluralistic healthcare system and gender-sensitive culture. This change in paradigm will symbolize an opportunity for action on social determinants and for inventing healthy public policies, and not merely interventions for healthcare delivery (WHO 2005b). Health systems research must be another crucial add-on in this march toward MDGs, and it should encompass human resource requirements, financing, health service delivery mechanisms and, more importantly, socio-cultural determinants behind patterns of health service utilization (Task Force on Health Systems Research 2004). A practical and realistic approach, however, would be to identify and prioritize problems, analyze the socio-political system and then invest in selective interventions and reforms, together 
with the government and the private sector. To eliminate stunting among children, for instance, all interventions would call for an appreciation of the underlying determinants of under-nutrition, such as poverty, poor education, disease burden and lack of women's empowerment (Bhutta et al. 2008). Accelerating progress toward the MDGs in all contexts requires strengthening of public health programs, social mobilization and a concerted action beyond the health sector. MDGs cannot be achieved with disease-focused interventions alone; an overall strengthening of the health system is called for. Needless to say, this would be, in a sense, an achievement of yet another millennium goal, which is to develop a global partnership for sustainable development.

\section{References}

Black, R.E., L.H. Allen, Z.A. Bhutta, L.E. Caulfield, M. de Onis, M. Ezzati, et al. 2008. "Maternal and Child under Nutrition: Global and Regional Exposures and Health Consequences.” Lancet 371(9608): 243-60.

Bhutta, Z.A. 2004. "Pakistan and the Millennium Development Goals for Health: a Case of Too Little, Too Late?" Journal of College of Physicians and Surgeons Pakistan 14(9): 515-7.

Bhutta, Z.A., T. Ahmed, R.E. Black, S. Cousens, K. Dewey, E. Giugliani et al. 2008. "What Works? Interventions for Maternal and Child under Nutrition and Survival." Lancet 371(9610): 417-40.

Clemens, M. and T. Moss. 2004. What's Wrong with the Millennium Development Goals? Center for Global Development, Washington DC.

Dodd, R. and A. Cassels. 2006. "Health, Development and the Millennium Development Goals." Annals of Tropical Medicine \& Parasitology 100(5 \& 6): 379-87.

Fikree, F.F., H.R. Gray, H.W. Berendes and M.S. Karim. 1994. "A Community Based Nested Case Control Study of Maternal Mortality." International Journal of Gynaecology and Obstetrics 47(3): 247-55.

Gezairy, H.A. 2004. "The Grave Problems Being Faced by Our Health Sector.” Journal of Pakistan Medical Association 54(8): 430-3.

Government of Pakistan. 1993. Utilization of Rural Basic Health Services in Pakistan. Report of Evaluation Study. Ministry of Health and WHO: Islamabad.

Government of Pakistan. 1998. Demographic Indicators: 1998 Population Census. Population Census Organization, Statistics Division; Ministry of Economic Affairs and Statistics: Islamabad.

Government of Pakistan. 2000a. Utilization of Public Health Facilities in Pakistan. National Health Management Information System: Islamabad.

Government of Pakistan. 2000b. Local Government Plan. National Reconstruction Bureau. Chief Executive Secretariat: Islamabad.

Government of Pakistan. 2001. An Overview of the Health Sector: the Way Forward. Multi Donor Support Unit and Ministry of Health: Islamabad.

Government of Pakistan. 2002. Human Development Report. President's Task Force on Human Development: Islamabad.

Government of Pakistan. 2003. National Report on Pakistan Participatory Poverty Assessment: Between Hope \& Despair. Planning Commission: Islamabad.

Government of Pakistan. 2006. Economic Survey 2005-06. Finance Division: Islamabad.

Hunte, P. and F. Sultana. 1992. "Health Seeking Behavior and the Meaning of Medications in Balochistan, Pakistan." Social Science and Medicine 34(12): 1385-97.

Husain, S. and B.T. Shaikh. 2005. Stalling the HIV/AIDS Epidemic in Pakistan through Social Marketing. Journal of Pakistan Medical Association 55(7): 294-8.

Hyder, A.A., O.A. Khan, S.A. Shah, M.A. Memon, M.R. Khanani and S. Ali. 1999. "Sub-National Response in HIV/AIDS: a Case Study in AIDS Prevention and Control from Sindh Province, Pakistan.” Public Health 113: 39-43.

Islam, A. and M.Z. Tahir. 2002. "Health Sector Reform in South Asia: New Challenges and Constraints." Health Policy 60: 151-69.

Kazi, B.M., A. Ghaffar and M. Salman. 2000. "Healthcare Systems in Transition III. Pakistan, Part I. Pakistan's Response to HIV-Aids." Journal of Public Health Medicine 22(1): 43-7.

Khan, A. 1996. "Policy Making in Pakistan's Population Programme." Health Policy and Planning 11(1): 30-51. 
Kroeger, A. 1983. "Anthropological and Socio-Medical Healthcare Research in Developing Countries." Social Science and Medicine 17(3): 147-61.

Mangrio, N., B.T. Shaikh and M.M. Alam. 2007. "Issues and Challenges in Expanded Programme on Immunization in Sindh, Pakistan.” Journal of College of Physicians and Surgeons Pakistan 17(5): 308-9.

Mirza, I. and R. Jenkins. 2004. "Risk Factors, Prevalence, and Treatment of Anxiety and Depressive Disorders in Pakistan: Systematic Review.” British Medical Journal 328: 794.

National Institute of Health. 2003. Expanded Programme on Immunization: Financial Sustainability Plan 20032012. Federal EPI/CDD Cell, Ministry of Health, Government of Pakistan: Islamabad.

NIPS. 2007. Pakistan Demographic and Health Survey 2006-07: Preliminary Report. NIPS: Islamabad.

Nishtar, S. 2006. The Gateway Paper: Health Systems in Pakistan - A Way Forward. Pakistan's Health Policy Forum. Heartfile: Islamabad.

Pakistan Medical Research Council. 1998. Health Profile of People of Pakistan. National Health Survey of Pakistan. Pakistan Medical Research Council: Islamabad.

Population Action International. 2005. How Access to Sexual \& Reproductive Health Services Is Key to the Mdgs. Population Action International: Washington, DC:

Qazi, S. and B.T. Shaikh. 2007. "Social Marketing of Insecticide Treated Nets: Making a Case for Pakistan." Eastern Mediterranean Health Journal 13(2): 449-56.

Saleem, S. and E.F. Fikree. 2001. "Induced Abortions in Low Socio-Economic Settlements of Karachi, Pakistan: Rates and Women's Perspectives." Journal of Pakistan Medical Association 51(8): 275-9.

Shaikh, B.T., J. Hatcher and D. Haran. 2006. "Making Healthcare Systems More Responsive to Women in Pakistan." British Medical Journal 333: 971.

Shaikh, B.T. and J. Hatcher. 2005. "Health Seeking Behavior and Health Services Utilization in Pakistan: Challenging the Policy Makers." Journal of Public Health (Oxford) 27(1): 49-54.

Shaikh, B.T., F. Rabbani and M. Rahim. 2006. "Health Workers for Change: a Tool for Promoting Behavior Change Among Health Providers." Eastern Mediterranean Health Journal 12(3/4): 331-9.

Sheikh, N.S., A.S. Sheikh, R.U. Shan and A.A. Sheikh. 2003. "Awareness of HIV and AIDS Among Fishermen in Coastal Areas of Balochistan.” Journal of College of Physicians \& Surgeons of Pakistan 3(4): 192-4.

Siddiqi, S., I.U. Haq, A. Ghaffar, T. Akhtar and R. Mahaini. 2004. "Pakistan's Maternal and Child Health Policy: Analysis, Lessons and the Way Forward.” Health Policy 69: 117-30.

Steketee, R.W., B.L. Nahlen, M.E. Parise and C. Menendez. 2001. "The Burden of Malaria in Pregnancy in Malaria Endemic Areas." American Journal of Tropical Medicine and Hygiene 64(Suppl 1-2): 28-35.

Task Force on Health Systems Research. 2004. "Informed Choices for Attaining the Millennium Development Goals: Towards an International Cooperative Agenda for Health-Systems Research.” Lancet 364: 997-1003.

Tinker, A.G. 1998. Improving Women's Health in Pakistan. Health, Nutrition and Population Series. World Bank: Washington DC.

United Nations Children's Education Fund (UNICEF). 2007. The State of the World's Children 2007. Women and children: The double dividend of gender equality. UNICEF: New York.

United Nations Development Programme (UNDP). 2005. Human Development Report 2005. "International cooperation at a crossroads: Aid, trade and security in an unequal world". UNDP: New York.

United Nations. 2001. General Assembly 56th Session. Road Map Towards the Implementation of the United Nations Millennium Declaration. Report of the Secretary-General: New York. Retrieved March 10, 2008. <http://www.un.org/millenniumgoals/index.html>

United Nations. 2007. The Millennium Development Goals Report 2007. United Nations: New York

Waters, H., L. Hatt and H. Axelsson. 2002. Working with the Private Sector for Child Health. Health, Nutrition and Population (HNP) Discussion Paper. World Bank: Washington DC.

World Bank. 1993. World Development Report 1993: Investing in Health. World Bank: Washington, DC.

World Bank. 1997. Pakistan: Towards A Health Sector Strategy. Health, Nutrition \& Population Unit, South Asia region: Washington DC

World Bank. 2000. Entering the 21st Century: World Development Report 1999/2000. World Bank: Washington DC.

World Bank. 2002. Pakistan Poverty Assessment. Poverty in Pakistan: Vulnerabilities, Social Gaps, and Rural Dynamics. Poverty Reduction and Economic Management Sector Unit South Asia Region: Geneva 
World Bank. 2004. The Millennium Development Goals for Health: Rising to the Challenges. World Bank: Washington, DC.

World Bank. 2005a. Accelerating progress towards achieving the MDG to improve maternal health: A collection of promising approaches. Health, Nutrition and Population (HNP) Discussion Paper. World Bank: Washington, DC.

World Bank. 2005b. Attaining the Millennium Development Goals in Pakistan: How likely and what will it take to reduce infant mortality, child malnutrition, gender disparities and to increase school enrollment and completion? South Asia Human Development Sector: Islamabad.

World Bank. 2007. Millennium Development Goals: Confronting the Challenges of Gender Equality and Fragile States. World Bank: Washington, DC.

World Health Organization (WHO). 2000a. World Health Report 2000: Health Systems: Improving Performance. WHO: Geneva.

WHO. 2000b. Roll Back Malaria Info Sheet. WHO: Geneva.

WHO. 2002. Roll Back Malaria in the WHO Eastern Mediterranean Region. Regional Office for the Eastern Mediterranean: Cairo.

WHO. 2005a. Health and the Millennium Development Goals. WHO: Geneva.

WHO. 2005b. Action on the Social Determinants of Health: Learning from Previous Experiences. A background paper prepared for the Commission on Social Determinants of Health. WHO: Geneva.

WHO. 2006. World Health Report 2006: Working Together for Health. WHO: Geneva.

Zaidi, A.K.M., T.A. Khan and D.S. Akram. 2004. "Early Child Health and Survival in Pakistan”. In Z.A. Bhutta, ed, Maternal and Child Health in Pakistan: Challenges and Opportunities. Karachi: Oxford University Press. 